\title{
Multiple/Overlap Autoimmune Syndrome: An Overlap of Systemic Lupus Erythematosus, Dermato-polymyositis and Non-insulin Dependent/Adult Onset Diabetes Mellitus Concomitant Herpes (Varicella) Zoster/Shingles, an Innovation
}

\section{Virendra N Sehgal ${ }^{1 *}$ and Rajesh Malhotra ${ }^{2}$}

${ }^{1}$ Department of Dermato-Venereology (Skin/VD) Center, Sehgal Nursing Home, Panchwati, Delhi-110 033, India

${ }^{2}$ Department of Orthopedics, All India Institute of Medical Sciences, New Delhi, India

*Corresponding author: Sehgal VN, Department of Dermato-Venereology (Skin/VD) Center, Sehgal Nursing Home, Panchwati, Delhi-110 033, India, Tel: 011-27675363; Fax: 91-11-2767-0373; Mob: 98101-82241; E-mail: sehgalvn@yahoo.co.in; drsehgal@ndf.vsnl.net.in.

Received date: April 16, 2018; Accepted date: May 15, 2018; Published date: May 20, 2018

Copyright: ( 2018 Sehgal VN, et al. This is an open-access article distributed under the terms of the Creative Commons Attribution License, which permits unrestricted use, distribution, and reproduction in any medium, provided the original author and source are credited.

\begin{abstract}
Multiple/overlap autoimmune syndrome, comprising systemic lupus erythematosus, dermato-polymyositis, and non-insulin dependent/adult onset diabetes mellitus is being reported in a 53-year-old woman. The diagnosis of each of them was based on cardinal clinical criteria supplemented by laboratory undertones. The drug delivery (management) and approaches (strategies), in particular takes cognizance of stability and acceptable improvement, but for abrupt multiple group vesicular eruption over the erythomatosus base accompanied by numbness, tingling and pain essentially afflicting the right forehead and the face for which acyclovir was administered in recommended dosages for herpes zoster vericella (shingles).
\end{abstract}

\section{Introduction}

Multiple autoimmune/overlap [1-5] syndromes are well-known phenomenon, and have been gathering momentum time and again. The credit of its initial perception [1,2] was visualize in early 1988 where concomitant occurrence of vitiligo, alopecia areata, Crohn's disease, form the subject matter for the future attention, thus setting the ball rolling that one autoimmune disease made predispose to yet another [5], a conceptual hypothesis, which needs astute indulgence to diversify and enrich the literature and through current case report.

\section{Case Report}

A 53-year-old woman, weighing $54 \mathrm{~kg}$, a well-established case of systemic lupus erythemetosus (SLE), based on the criteria for its classification [6] as well as clinical practice guidelines [7] that included fever, feeling tired, red rash, painful and swollen joints, occasional chest pain, hair loss, in particular, alopecia totalis, recurrent mouth ulcers and swollen lymph nodes were the features of systemic LE whereas, the diagnosis of polymyositis was made on the basis of dysphagia, rapid onset ( $<4$ weeks) of myositis, cutaneous necrosis and vasculitis, conforming to the criteria laid down for dermatomyositis and polymyositis. The concomitance of systemic lupus erythematosus and dermatomyositis/polymyositis has been a fascinating overture, and now stands well-recognized as an overlap syndrome $[5,8]$ therefore, warranted elaborate laboratory background comprising several interrelated parameters, the salient details of which are being portrayed in the following (Table 1) for ready reference. In addition, the diagnosis of polymyositis was undertaken on the muscle biopsy of affected gastrocnemius muscle of the thigh, which depicted marked in fibre size variation along with fat infiltration, and minimal perimysical fiberosis. There was no evidence of peri-fascicular atrophy or significant inflammation. Fibre typing and myofibrillar achitechture was maintained. Immuno-histochemistry of spectrum, alpha $(\alpha)$, beta $(\beta)$, gamma $(\gamma)$, delta $(\delta)$, sarcoglycan, dysferelin. Lamerin and emerin showed reservation in muscle fibres. Human leukocyte antigen (HLA) 1 and 2 were not overexpressed, and were within normal limits, features suggestive of that of a myopathy.

\begin{tabular}{|l|l|l|l|}
\hline Test name & \multicolumn{1}{l|}{ Results } & Units & Bio. Ref. interval \\
\hline Complete Haemogram Test or Complete Blood Count (CBC) & 11.6 & $\mathrm{~g} / \mathrm{dl}$ & $12.5-16.0 \mathrm{~g} / \mathrm{dl}$ \\
\hline Haemoglobin (Hb) & 6900 & $/$ cumn & $4000-11000 / \mathrm{cumm}$ \\
\hline Total Leucocyte Count (TLC) & 73 & $\%$ & $40-75$ \\
\hline Differential Leucocytic Count (D.L.C) & 18 & $\%$ & $20-40$ \\
\hline Neutrophil & & \\
\hline Lymphocyte & & \\
\hline
\end{tabular}


Citation: Sehgal VN, Malhotra R (2018) Multiple/Overlap Autoimmune Syndrome: An Overlap of Systemic Lupus Erythematosus, Dermatopolymyositis and Non-insulin Dependent/Adult Onset Diabetes Mellitus Concomitant Herpes (Varicella) Zoster/Shingles, an Innovation. J Dermatitis 3: 113.

Page 2 of 3

\begin{tabular}{|c|c|c|c|}
\hline Eosinophil & 5 & $\%$ & 6-Jan \\
\hline Monocyte & 4 & $\%$ & $10-F e b$ \\
\hline Erythrocyte Sedimentation Rate (E.S.R) (westergren) & 18 & $\mathrm{~mm} / \mathrm{hr}$ & 20-Jan \\
\hline Packed cell volume (P.C.V) & 36.7 & $\%$ & $35.0-6.50$ \\
\hline Red Blood Cells (RBCs) & 4.26 & Million/cmm & $3.50-5.50$ \\
\hline Platelet Count & 3.08 & Lakh/cmm & $1.50-4.50$ \\
\hline Mean Corpuscular Vol (MCV) & 86.2 & $\mathrm{fl}$ & $80.0-99.0$ \\
\hline Mean Corpuscular Haemoglobin (MCH) & 27.2 & PICOGRAM & $27.0-31.0$ \\
\hline Mean Corpuscular Haemoglobin Concentration (MCHC) & 31.6 & $\mathrm{gm} / \mathrm{dl}$ & $33.0-37.0$ \\
\hline Red Cell Distribution Width (R.D.W) & 15.6 & $\%$ & $11.5-14.5$ \\
\hline
\end{tabular}

Table 1: Laboratory investigation; depicting name of the test; Results; units and Bio. Reference interval.

\section{Drug delivery (management) and approaches (strategies)}

Consequent upon aforementioned revelations, treatment comprising $50 \mathrm{mg}$ of prednisolone (Orapred, Prelone) once a day after breakfast adequate to stabilize the condition, supplemented by oral administration of pantaprazole (Protonix, pantocid) $40 \mathrm{mg}$, telmisartran (Twynsta, telma) $20 \mathrm{mg}$, calcium carbonate (Bio max 3D) $500 \mathrm{mg}$, methylcobalamin $1500 \mathrm{MCG}$, calcitrol $0.25 \mathrm{mcg}$ for a period of 90 days. During the period a perceptible overall amelioration was a benchmark for tapering a dose of prednisolone $9-10 \mathrm{mg}$ by every 30 days until a maintenance dose of $10 \mathrm{mg}$ azathioprine 10 (Imuran, Azasan) to $50 \mathrm{mg} 2$ times a day, an adjunct therapy was added as a replacement therapy. Incidentally, the patient had high fluctuating blood sugar levels, which were detected over a period of time, apparent in the form of frequent urination, increased thirst, and increased hunger, non-insulin dependent/adult onset diabetes mellitus [9-12] type-2. She is also been treated by human mixtard 30/70 100 iu injection 35 unit before the major meals in the morning and 35 units in the evening. During the course of the treatment the patient was taken aback by sudden appearance of blisters affecting the right side of the face and forehead, and reported to the outpatients' with the complaints of excruciating pain, redness, swelling, and blistering affecting exclusively the right side of the face of 8 days duration. Initially, she had experienced numbness, tingling, and pain, which during the $48 \mathrm{~h}$ usher in with preceding features [13].

On skin surface examination, facial appearances were conspicuous, and studded with vesicles and/or blisters largely in groups/clusters. They were numerous. A few discreet vesicles or blisters intersperse between the groups were also seen. The background of these lesions was erythematous, there was marked edema of the face. Essentially, the lesions were ipsilateral afflicting right half of the face only (Figure 1). Accordingly, acyclovir [14] (Zovirax, Sitavig) $800 \mathrm{mg}$ was administered 5 times daily for a period of 10 days, with complete regression of lesions leaving behind pigmented macules.

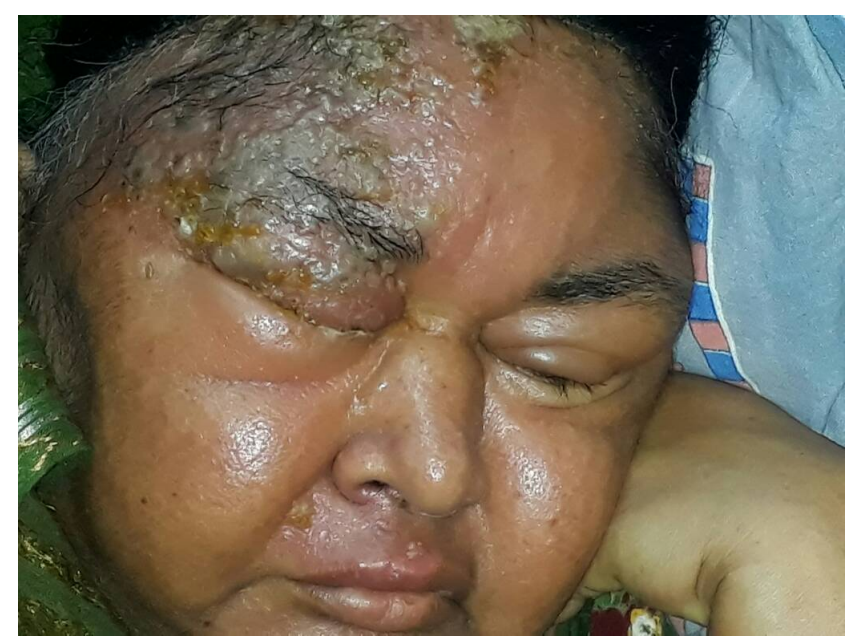

Figure 1: Herpes (varicella) zoster /shingles in Systemic lupus erythematosusmyositis overlap syndrome and Adult-Onset Diabetes Mellitus: Herpes zoster displaying group vesiculo bullous lesion on the erythematosus background, occupying the right forehead and the cheek with prominent face edema, alopecia totalis wearing a wig.

\section{Discussion}

Multiple [2,3,5] autoimmune syndrome, is a fascinating caption has been in vogue ever since its inception-1, in the year 1988 and exclusive account of which was emphasize later as Multiple Autoimmune Syndrome (MAS). The scope of this term can be enlarge to include one or several autoimmune disease for one autoimmune disease may predispose itself to yet another autoimmune disease(s), inferring their overlap, an Overlap Autoimmune Syndrome (OLAS) thus Multiple Autoimmune Syndrome (MAS) and Overlap Autoimmune Syndrome are interchangeable and could be conveniently make use of in an exigency.

However, only a few scintillating report could be identified, despite it being an astounding challenge not only for its clinical, but also far 
Citation: Sehgal VN, Malhotra R (2018) Multiple/Overlap Autoimmune Syndrome: An Overlap of Systemic Lupus Erythematosus, Dermatopolymyositis and Non-insulin Dependent/Adult Onset Diabetes Mellitus Concomitant Herpes (Varicella) Zoster/Shingles, an Innovation. J Dermatitis 3: 113.

Page 3 of 3

laboratory collaterals, considered essential to arrive at their precise diagnosis. It is true for both SLE as well as dermato-polymyositis.

The two well recognized autoimmune diseases the challenging pillars, inviting strenuous endeavors both for diagnosis and therapy. Non-Insulin dependent type-2/Adult Onset Diabetes Mellitus may yet be another component of multiple/overlap autoimmune syndrome, adding new dimensions Furthermore, it is therefore worthwhile to form an overview of three or more autoimmune diseases available thus far, with a focus, in particular, based on the analysis of 87 cases till 1988 from across the globe- 1 suggesting a comprehensive classification for the future use. The recitation of which may provide glimpses into the future guidelines.

Type-I comprises myasthenia, thymoma, polymyositis and giant cell myocarditis.

Type-II includes the Sjögren's syndrome, rhumatoid arthritis, primary biliary cirrhosis, scleroderma and autoimmune thyroid disorders.

Type-III groups together 10 autoimmune diseases (autoimmune thyroid disease, myasthenia and/or thymoma, Sjögren's syndrome, pernicious anaemia, idiopathic thrombocytopaenic purpura, Addison's disease, insulin-dependent diabetes, vitiligo, autoimmune haemolytic anaemia, systemic lupus erythematosus).

An elaborate search on multiple/overlap autoimmune syndrome was found to be absolutely depleted, except for an occasional report-2 in the year 2014. This particular case report therefore, is paramount and had vitiligo, alopecia areata, crohn's disease, psoriasis vulgaris and oral lichen planus to focus attention to the subject in order to create awareness for picking and choosing such cases in the future. Accordingly, reports of permutation and combination of multiple autoimmune diseases corresponding to type-1 [15], type-2 [16] and type-3 $[17,18]$ were identified and delineated. The minute details of drug delivery (management) and approaches (strategies) challenging perspective for need careful designing to achieve optimum amoleration in the condition. Herpes (varicella) zoster/shingles may be one of them and has rarely been reported in SLE [19] and polymyositis [20] which may either be due to iatrogenic/coincidental or immunocompromised [21].

\section{References}

1. Humbert P, Dupond JL (1988) Multiple autoimmune syndromes. Ann Med Interne 139: 159-68.

2. Santos G, Sousa L (2014) Syndrome in question. Multiple autoimmune syndrome. An Bras Dermatol 89: 361-362.
3. Mohan MP, Ramesh TC (2003) Multiple autoimmune syndrome. Indian J Dermatol Venereol Leprol 69: 298-299.

4. Masood S, Sajid S, Jafferani A, Tabassum S, Ansar S (2014) Multiple autoimmune syndromes associated with psoriasis: a rare clinical presentation. Oman Med J 29: 130-131.

5. Maazoun F, Frikha F, Snoussi M, Kaddour N, Masmoudi H, et al. (2011) Systemic lupus erythematosusmyositis overlap syndrome: report of 6 cases. Clin Pract 1: e89.

6. Smith EL, Shmerling RH (1999) The American College of Rheumatology criteria for the classification of systemic lupus erythematosus: strengths, weaknesses, and opportunities for improvement. Lupus 8: 586-595.

7. Trujillo-Martín MM, de Larrinoa RFFI, Ruíz-Irastorza G, Pego-Reigosa JM, Sabio Sánchez JM, et al. (2016) Clinical practice guidelines for systemic lupus erythematosus: Recommendations for general clinical management. Med Clin (Barc) 146: 413.

8. Miller FW, Rider LG, Plotz PH, Isenberg DA, Oddis CV (2003) Diagnostic criteria for polymyositis and dermatomyositis. Lancet 362: 1762-1763.

9. Sehgal VN, Malhotra R, Verma P, Bhattacharya S (2018) Glucocorticoids (GCs): Immunosuppressive drugs /Adjuvant drugs Delivery/ Management and Approaches /strategies. Indian J Dermatol (In press).

10. Sehgal VN, Malhotra R (2018) Glucocorticoids (GCs)/Corticosteroids/ Steroids Sparing (Replacement) Maintenance Immunosuppressive/ Adjunct therapy Drugs' Delivery And Approaches Pharmacology and Therapeutics contemporary status. Skinmed (In press).

11. World Health Organization (2014) Diabetes.

12. World Health Organization (2013) Diabetes Fact sheet.

13. Centers for Disease Control and Prevention (2014) Shingles (Herpes Zoster) Signs \& Symptoms.

14. Ahmed AM, Brantley JS, Madkan V, Mendoza N, Tyring SK (2007) Managing herpes zoster in immuno-compromised patients. Herpes 14: 32-36.

15. Jordan B, Eger K, Zierz S (2009) Polymyositis associated with thymoma. Nervenarzt. 80: 708-11.

16. Selmi C, Meroni PL, Gershwin ME (2013) Primary biliary cirrhosis and Sjogren's syndrome: Autoimmune epithelitis. J Autoimmun 39: 34-42.

17. Bach JF (1994) Insulin-dependent diabetes mellitus as an autoimmune disease.Endocr Rev 15: 516-542.

18. Zarbo A, Isedeh P, Jacobsen G, Lim HW, Hamzavi I (2016) Comorbid autoimmune diseases in patients with vitiligo: A cross-sectional study. J Am Acad Dermatol 74: 295-302.

19. Manzi S, Kuller LH, Kutzer J, Pazin GJ, Sinacore J, et al. (1995) Herpes zoster in systemic lupus erythematosus. J Rheumatol 22: 1254-1258.

20. Nagaoka S, Tani K, Ishigatsubo Y, Chiba J, Kato K, et al. (1990) T.Herpes zoster in patients with polymyositis and dermatomyositis. Kansenshogaku Zasshi 64: 1394-1399.

21. Dworkin RH, Johnson RW, Breuer J, Gnann JW, Levin MJ, et al. Recommendations for the management of herpes zoster. Clin Infect Dis 44 Suppl 1: S1. 